\title{
Space Adaptation Back Pain A Retrospective Study
}

\author{
Presenter: Eric Kerstman M.D., MPH \\ NASA Johnson Space Center/Wyle/UTMB \\ ekerstman@wylehou.com \\ (281) $212-1305$ \\ Aerospace Medical Association \\ $80^{\text {th }}$ Annual Scientific Meeting \\ Los Angeles, CA \\ May 2009
}




\section{Space Adaption Back Pain}

- Astronauts frequently report back pain in the early phase of space flight as they adapt to microgravity

- The epidemiology of space adaptation back pain (SABP) has not been well established

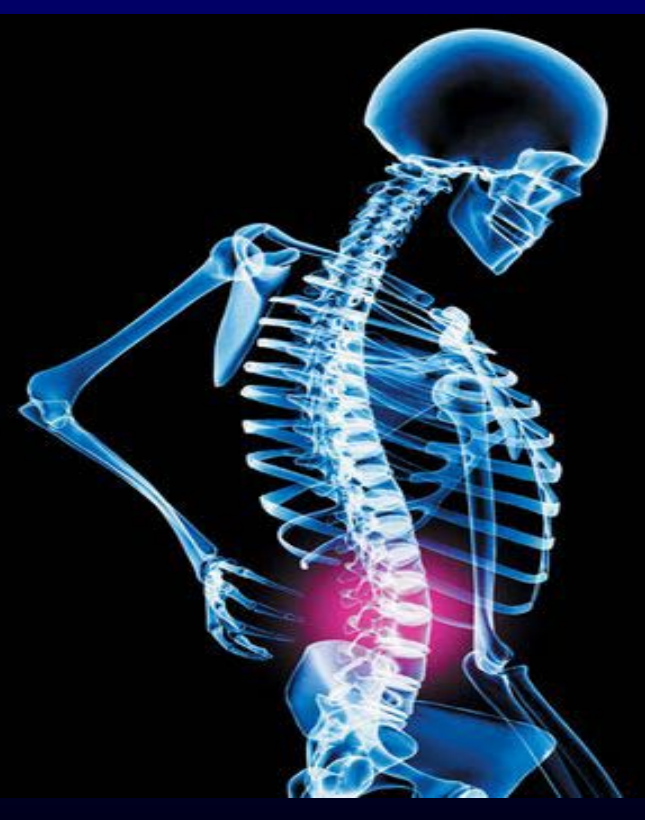




\section{Objectives}

- Determine the exact incidence of SABP among astronauts

- Develop a case definition of SABP

- Delineate the nature and pattern of SABP

- Review available treatments and their effectiveness in relieving SABP

- Identify any operational impact of SABP 


\section{Methods}

Retrospective review of all available mission medical records of astronauts in the U.S. space program, which included:

- Preflight medical exams

- Flight surgeon logs

- Postflight medical exams

- Postflight medical debriefs

- Standardized back pain questionnaire

- Private Medical Conference (PMC) Tool 


\section{Missions}

- Mercury

- Gemini

- Apollo

- $\quad$ Apollo-Soyuz Test Project (ASTP)

- $\quad$ Mir (U.S. Astronauts only)

- Skylab

- International Space Station (ISS) missions (Expedition 1 through 15)

- $\quad$ Shuttle missions STS-1 through STS-122 (Except STS-51L Challenger and STS-107 Columbia) 


\section{Study Size}

A total of 772 astronaut flights were reviewed

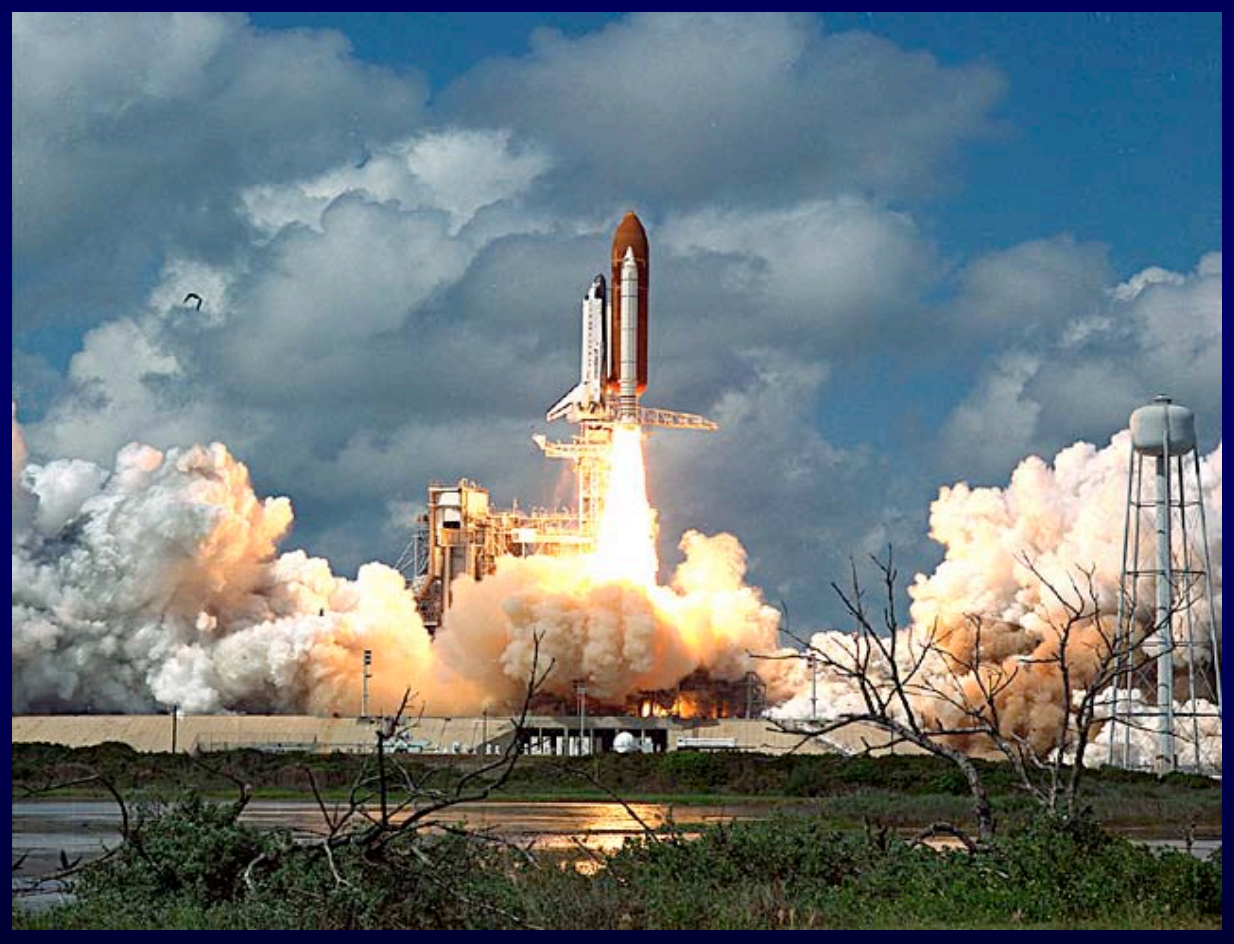




\section{Case Definition of SABP}

- Symptoms are not precipitated by an injury or related to prolonged recumbent sitting on the launch pad

- Symptoms develop within the first 5 days of space flight

- Multiple days of in-flight back pain were considered as one case

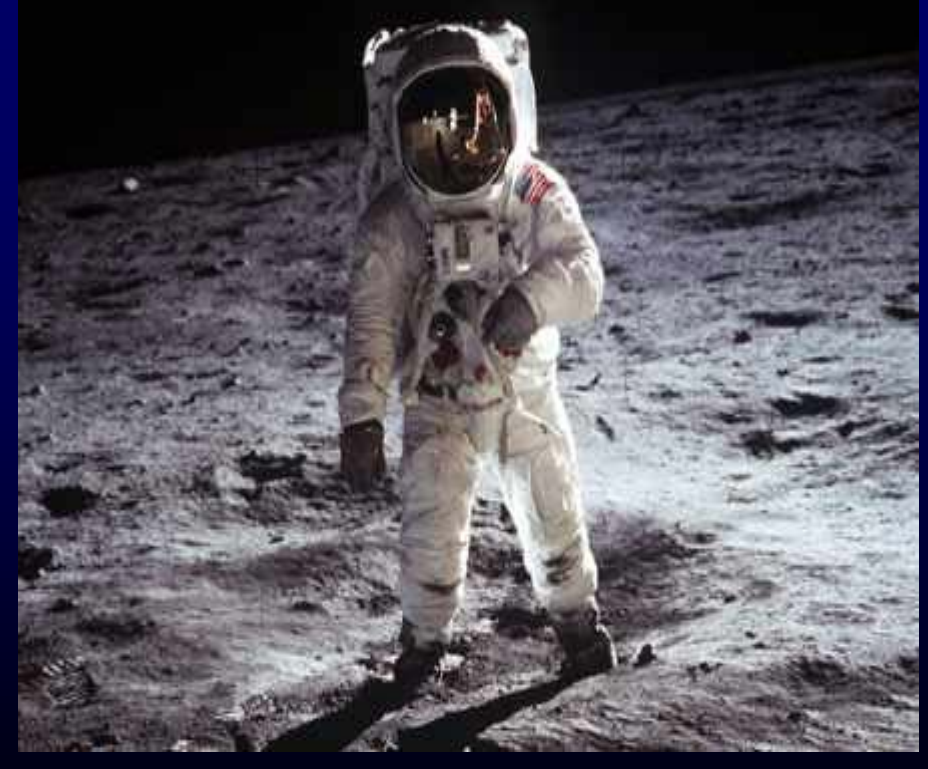




\section{Results}

\section{Incidence of SABP was 52\%}

\section{Back Pain among Astronauts}

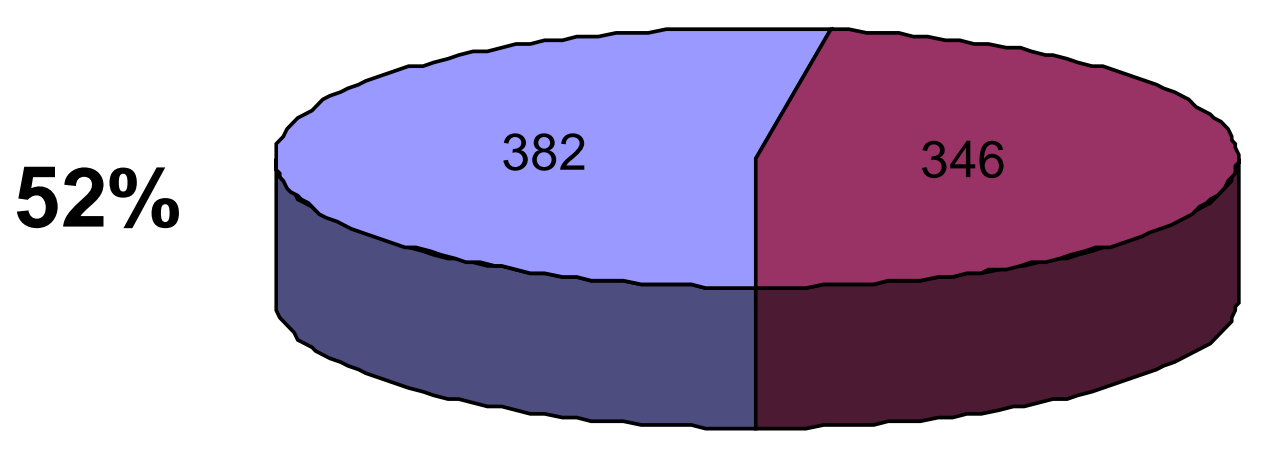

$\square$ Yes $\square$ No 


\section{Gender Analysis}

Comparison of Gender and Space Adaptation Back Pain

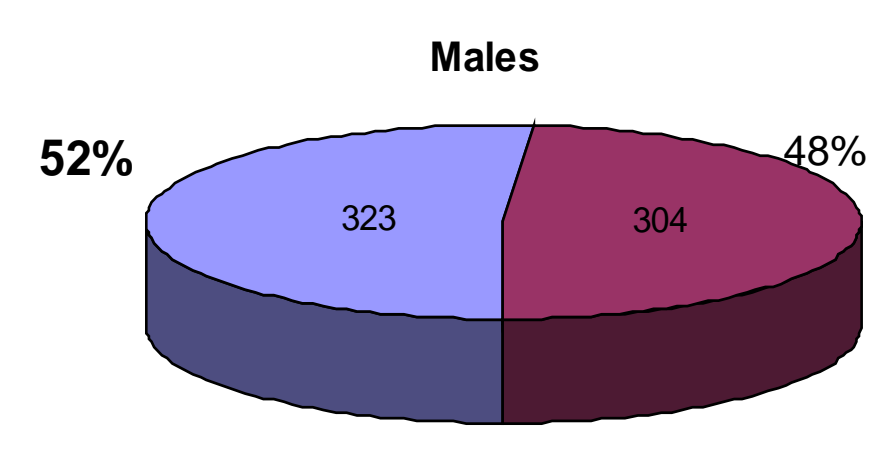

$\square$ SABP $\square$ No SABP

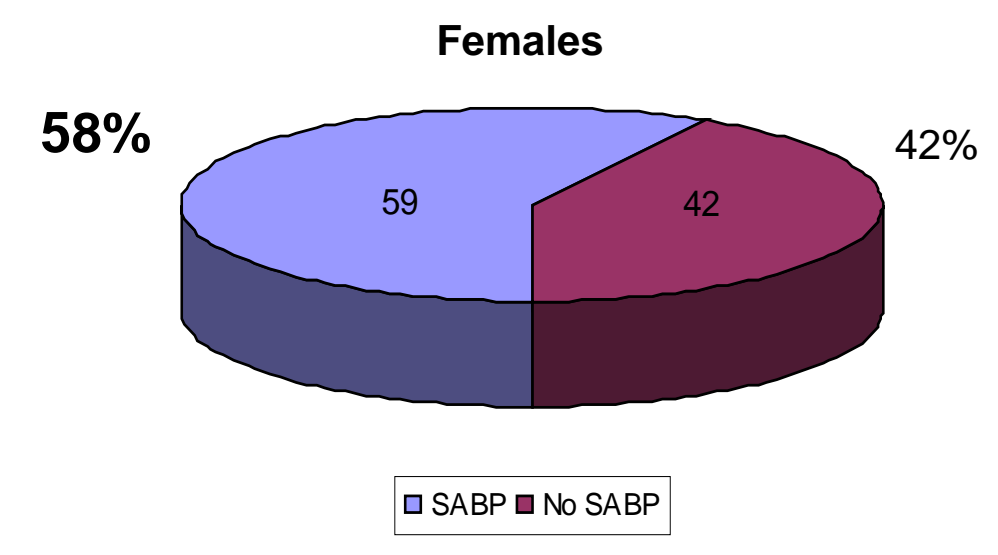

\section{Males}

SABP 52\%

\section{Females}

SABP 58\% 


\section{Shuttle Gender Analysis}

Shuttle SABP Analysis Males

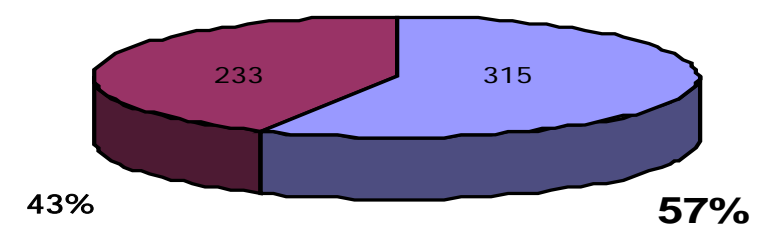

口 SABP
Shuttle SABP Analysis Females

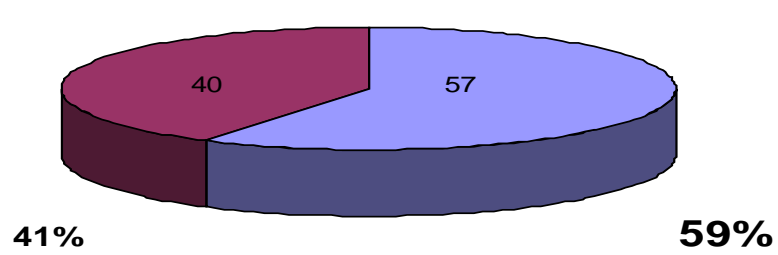

$\square$ SABP $\square$ No SABP
Males

SABP 57\%
Females

SABP 59\% 


\section{SABP Intensity}

\section{Pain Intensity}

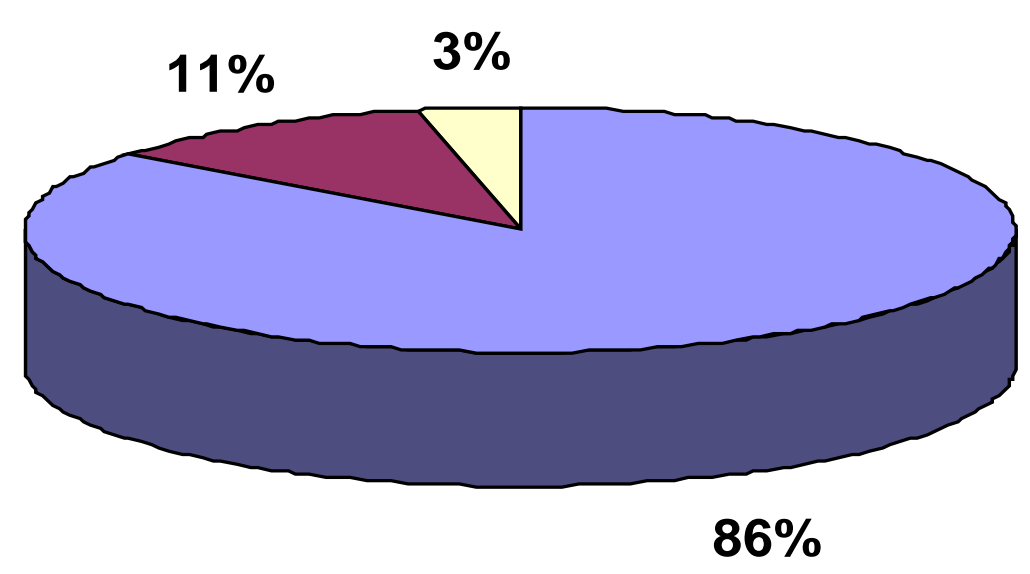

$\square$ Mild $\square$ Moderate $\square$ Severe

Mild pain $\quad 86 \%$

Moderate pain $\quad 11 \%$

Severe pain $\quad 3 \%$ 


\section{SABP Location}

\section{Back Pain Location}

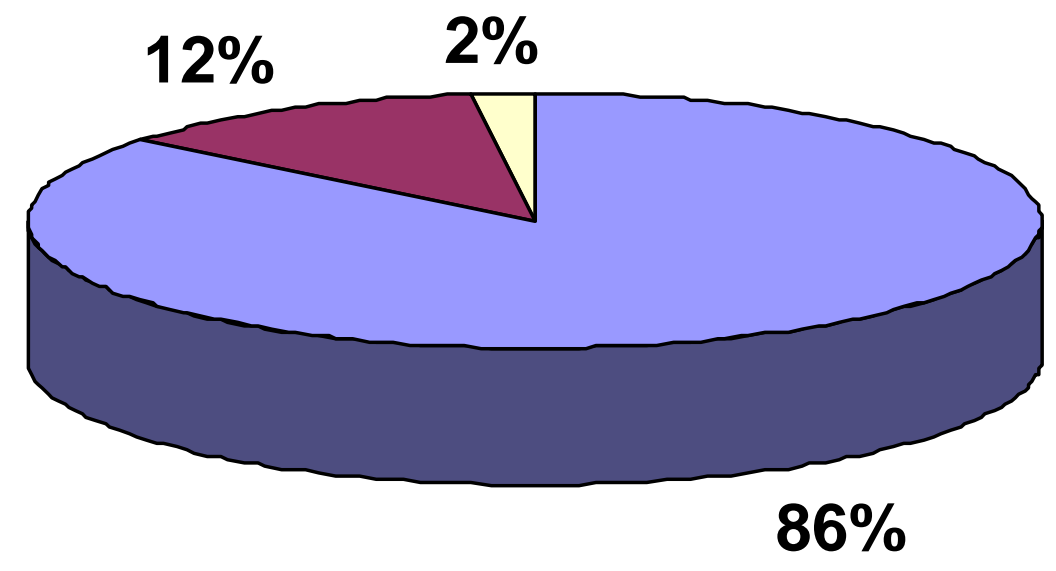

$\square$ Lumbar $\square$ Thoracic $\square$ Cervical

Lumbar $\quad 86 \%$

Thoracic $\quad 12 \%$

Cervical $2 \%$ 


\section{Onset of SABP}

In most SABP cases, the initial onset of symptoms was within the first 2 days of space flight. Only 12 astronauts reported an onset of symptoms after flight day 2

\section{INITIAL DAY SABP}

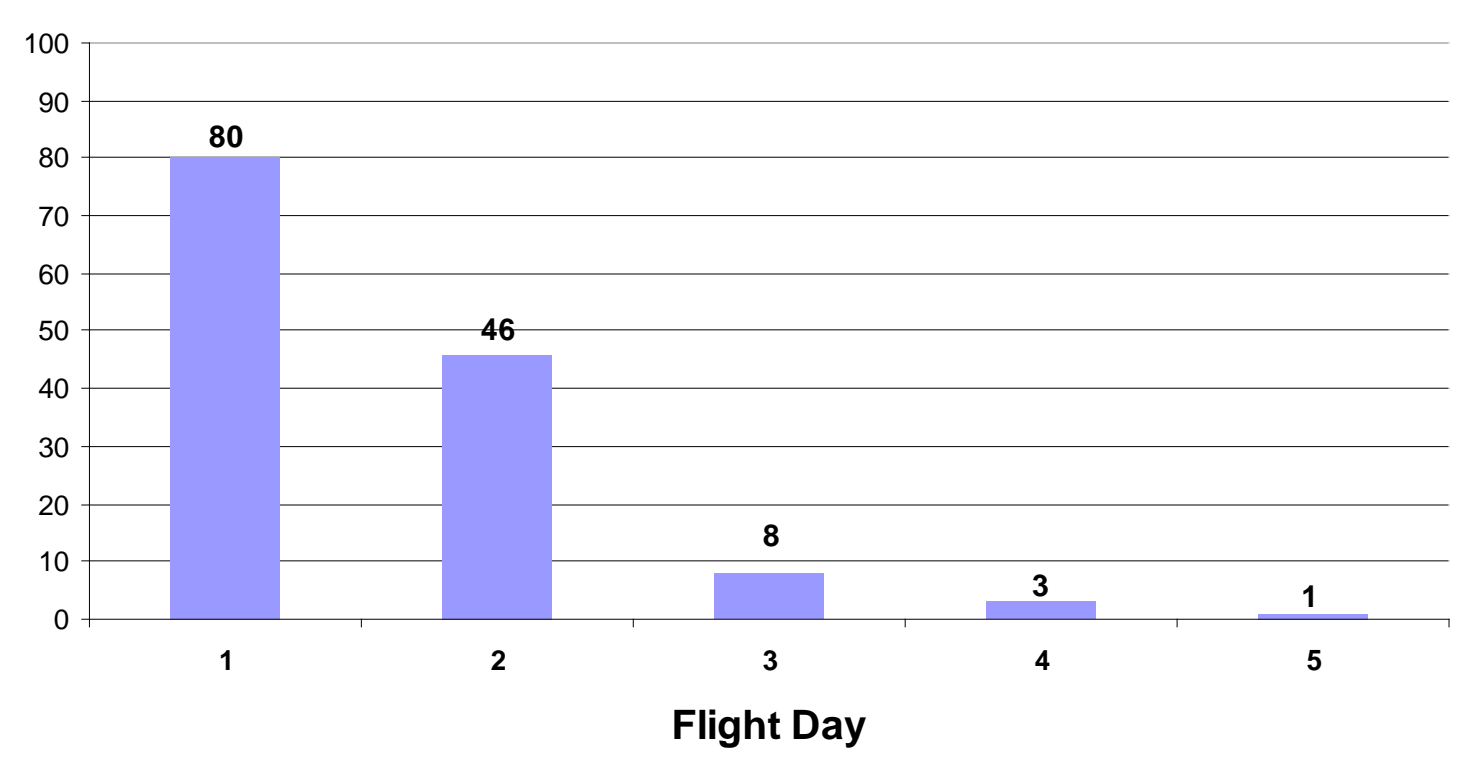




\section{SABP \& Flight Days}

SABP is present in the early phase of spaceflight, with a peak prevalence on flight day 2 and none reported after flight day 12

Flight Days Associated With SABP

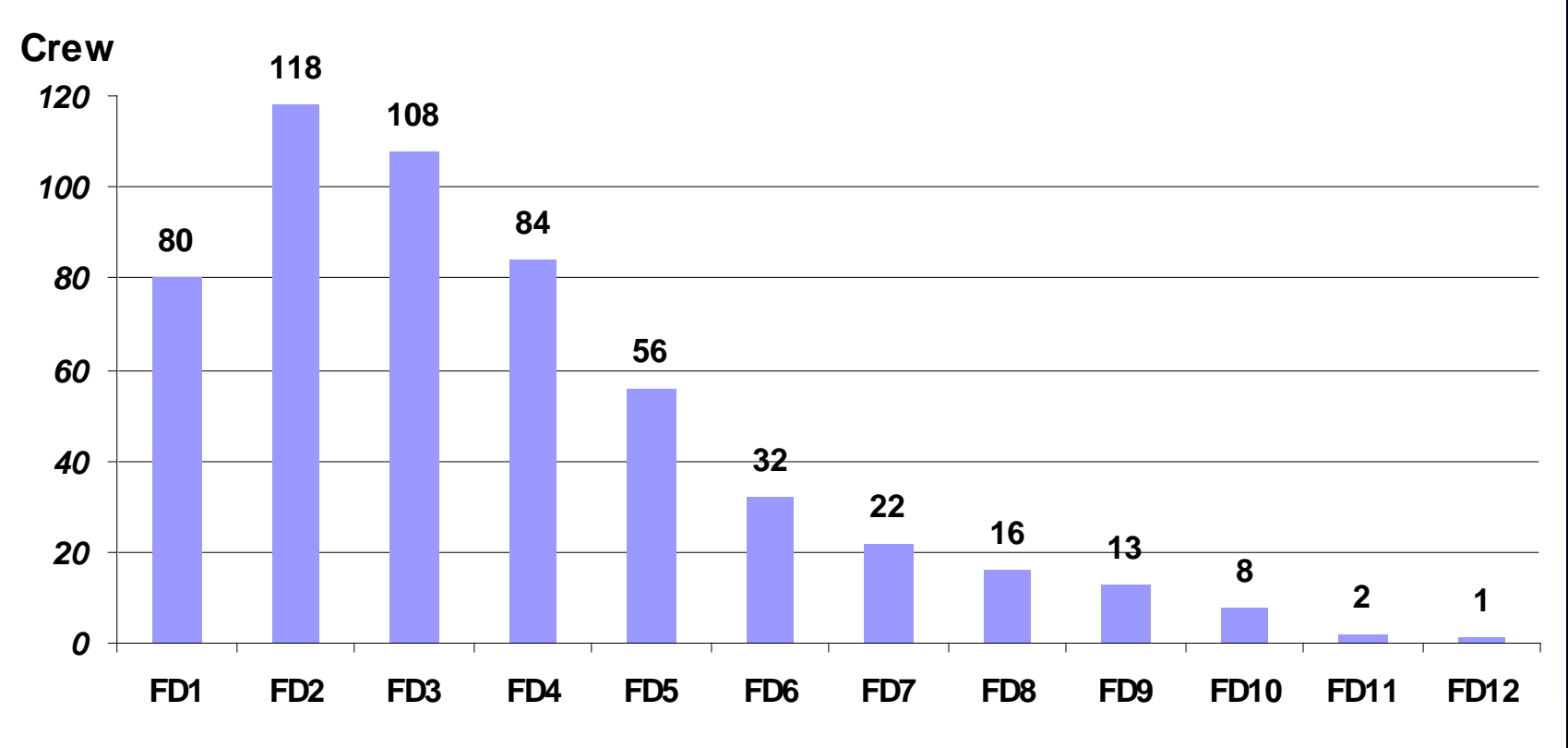




\section{Temporal Component}

Time of Day SABP Present

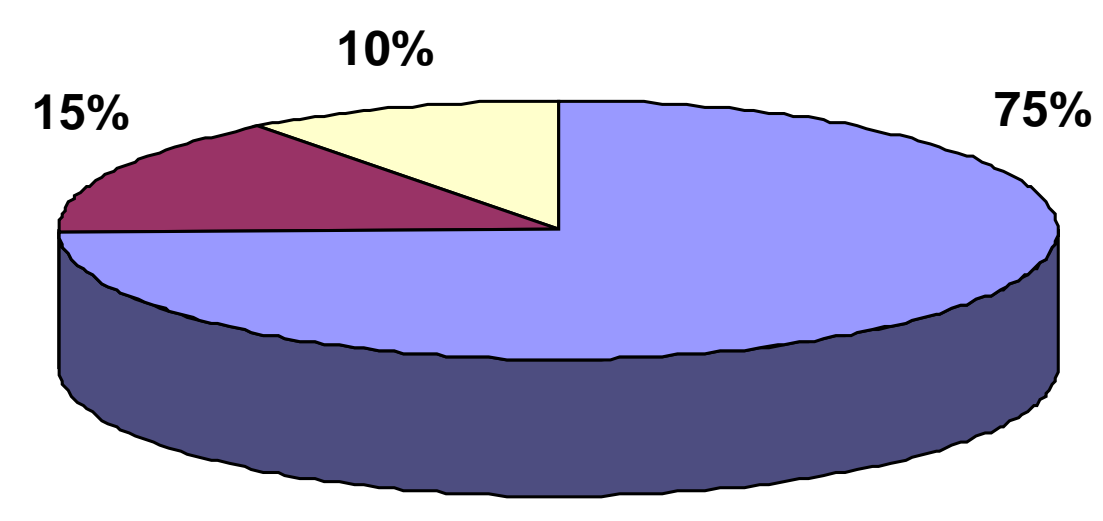

Night

Day

Both
$75 \%$

$15 \%$

$10 \%$ 


\section{Effectiveness of Treatments}

The most effective treatments were bending the knees to the chest (91\%), stretching the lumbar spine (90\%) and antiinflammatory medication (85\%)

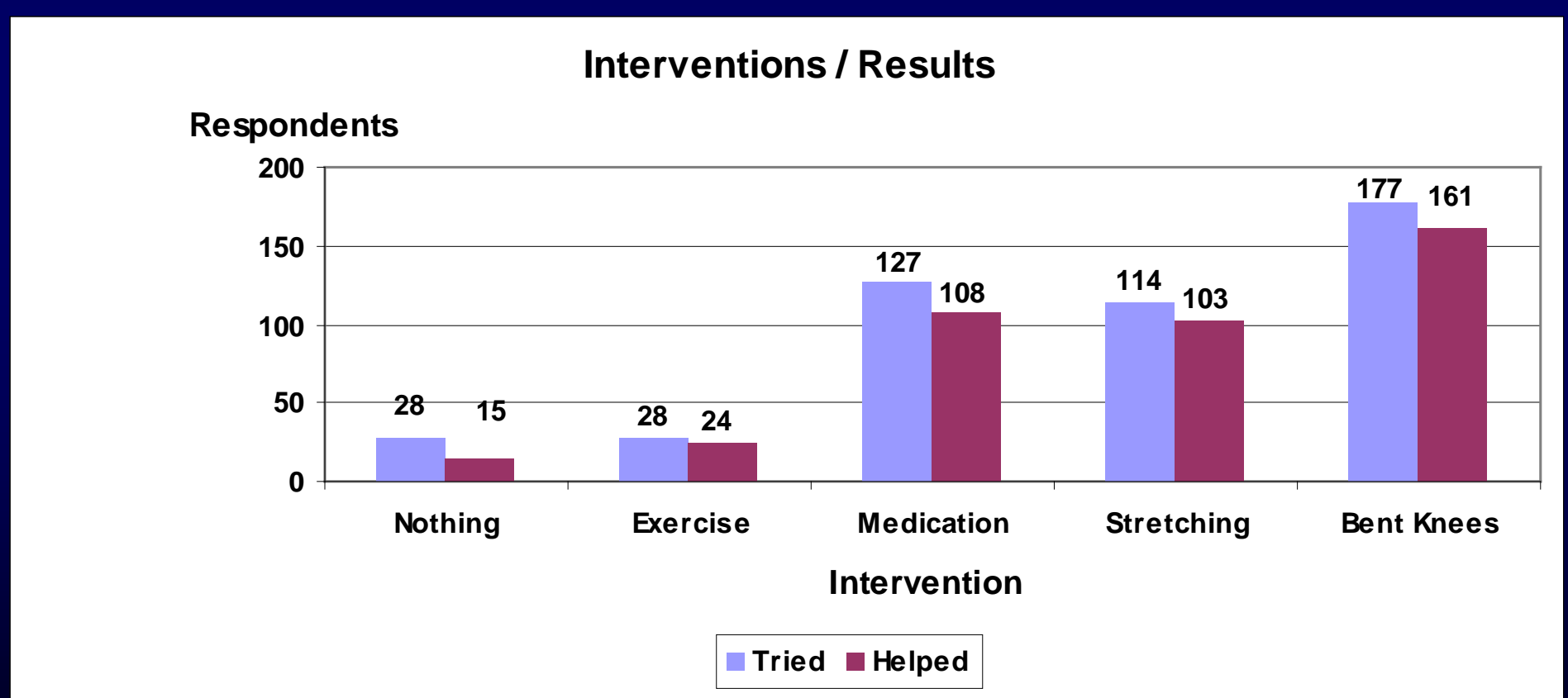




\section{Vehicle Analysis}

The incidence of SABP varied in relation to the space flight vehicle

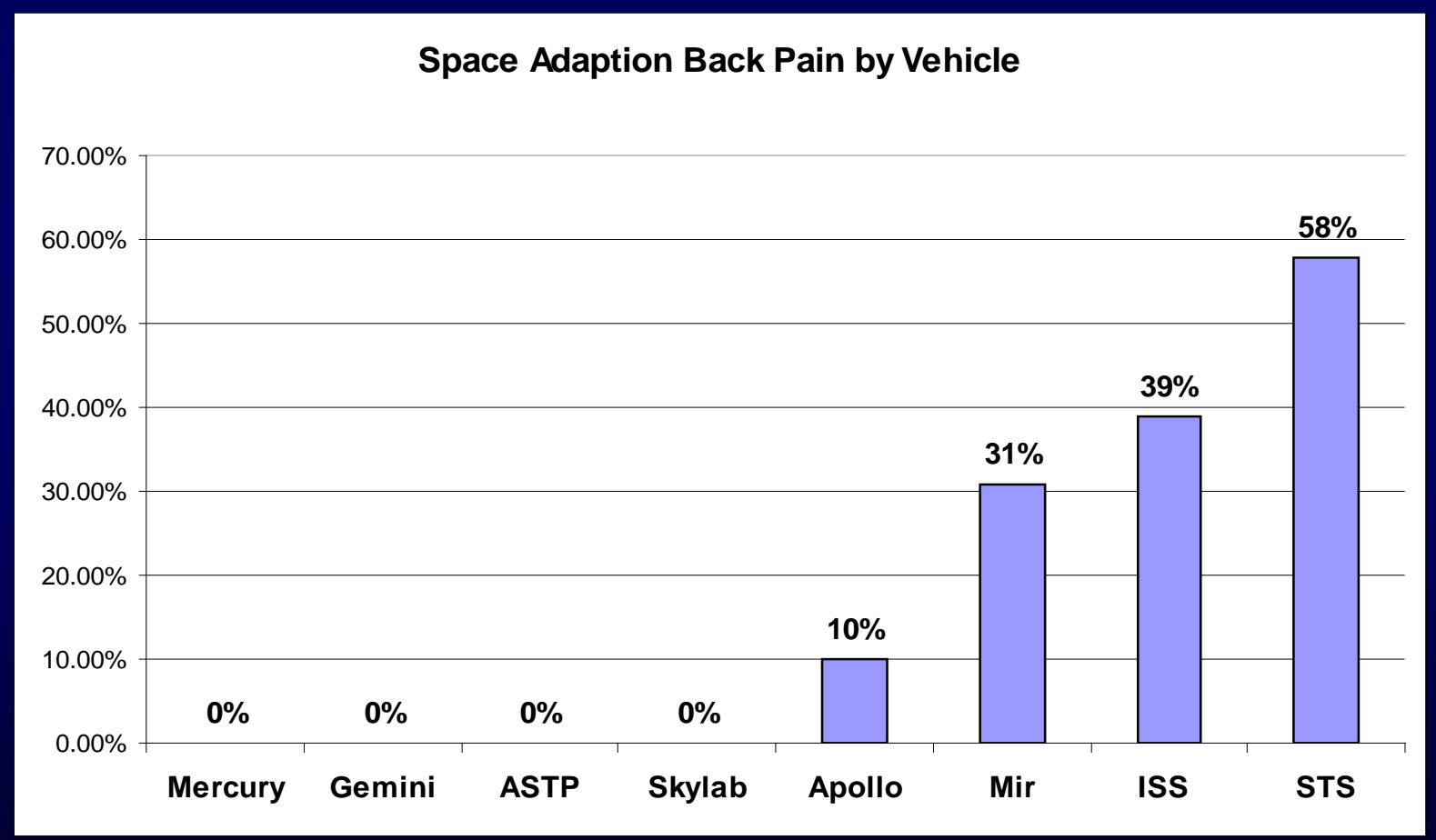




\section{History of Pre-flight Back Pain}

Positive History of Preflight Back Pain Anaylsis

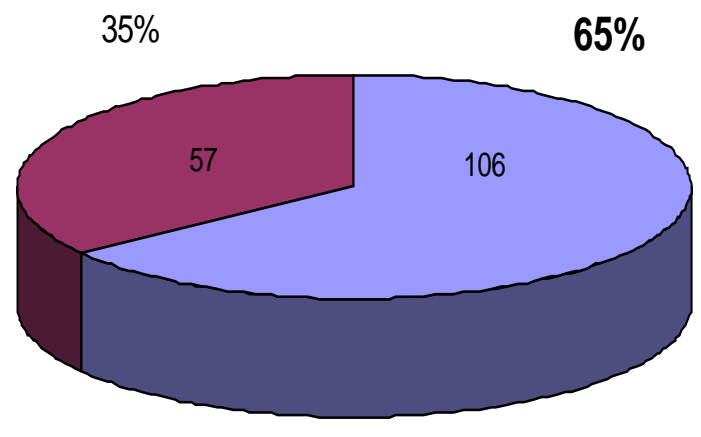

$\square S A B P=Y \square S A B P=N$

\section{Negative history of Preflight Back Analysis}

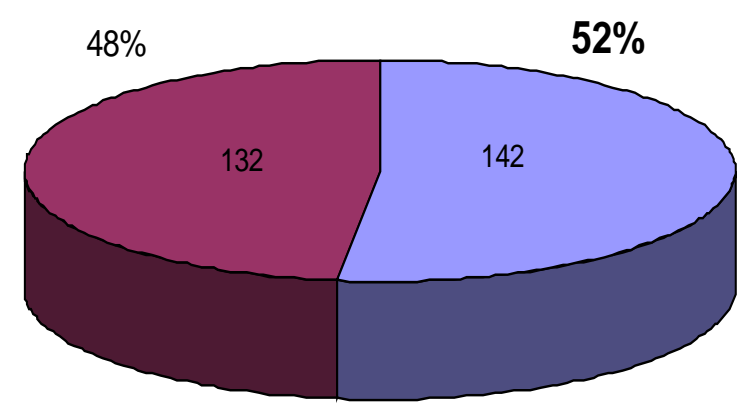

$\square \mathrm{SABP}=\mathrm{Y} \square \mathrm{SABP}=\mathrm{N}$
Positive History

SABP $65 \%$
Negative History

SABP 52\% 


\section{SABP Based on Number of Missions}

Among astronauts who flew more than one mission; they had a higher incidence of SABP on their first mission than on subsequent missions

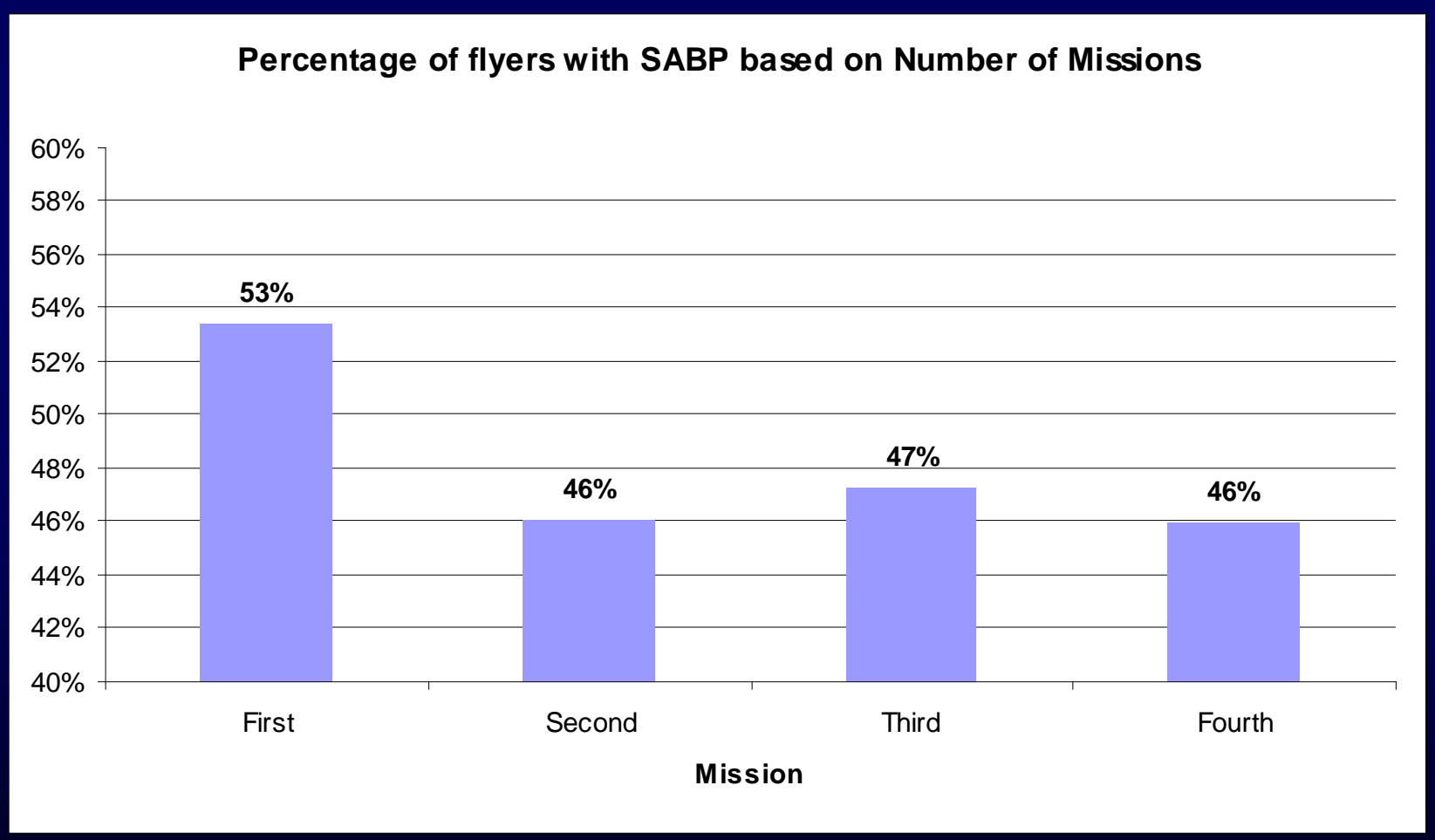




\section{SABP Characteristics}

- Symptoms are usually mild to moderate

- Symptoms are usually localized to the lumbar region

- Symptoms are described as an ache or stiffness

- Symptoms typically occur during the sleep period

- Neurological symptoms (radicular pain, numbness, tingling) are absent

- Symptoms tend to improve or resolve with the use of bending the knees to the chest, stretching of the lumbar spine, or anti-inflammatory medication 


\section{Conclusions}

- The incidence of SABP has been determined to be 53\% among astronauts in the U.S. space program

- Most cases of SABP are mild, self-limited, or respond to available treatments

- There are no currently accepted preventive measures for SABP

- It is difficult to predict who will develop SABP

- The precise mechanism and spinal structures responsible for SABP are uncertain

- There was no documented evidence of direct operational mission impact related to SABP

- There is potential mission impact related to uncontrolled pain, sleep disturbance, or the adverse side effects of antiinflammatory medications 


\section{Limitations}

- Retrospective study

- Missing data

- Misinterpretation of existing data

- Standardized back pain questionnaire only used on Shuttle missions

- Reluctance among astronauts to report in-flight back pain 


\section{Recommendations}

- Promote the most effective treatments of SABP with the least potential for adverse side effects

- Sleep accommodations on all space flight vehicles should allow for crewmembers to bend their knees to the chest

- The precise mechanism, spinal structures and causative factors associated with SABP should be further investigated in order to facilitate the development of preventive measures, as well as additional effective treatments 


\section{Acknowledgements}

Contributing authors:

RICK A. SCHEURING, D.O.

NASA Johnson Space Center, Houston, TX

MATT G. BARNES, M.D.

Dewitt Army Community Hospital, Fort Belvoir, VA

TYSON B. DEKORSE, M.D. MSU, Provo, UT

LYNN G. SAILE R.N. M.S.

Wyle, Houston, TX 


\section{Questions}

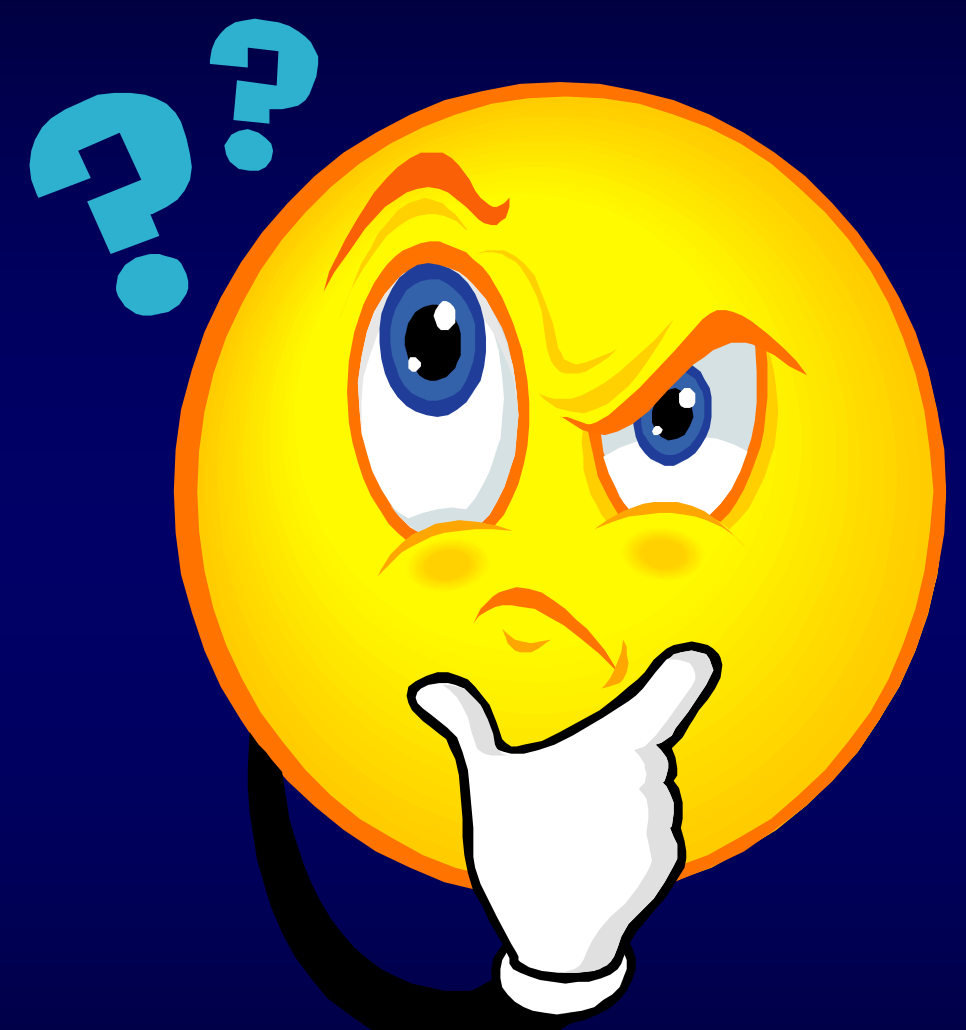




\section{References}

- $\quad$ Brown JW. Crew height measurement, the Apollo-Soyuz test project medical report. Washington DC: NASA: 1977, NASA SP-411.

- Davis JR, Vanderploeg JM, Jennings RT, Stewart DF. Space motion sickness during 24 flights of the space shuttle. Aviat Space Environ Med. 1998 Dec; 59 (12) 1185-89.

- Hutchinson KJ, Waterpaugh DE, Murthy G, Convertino VA, Hargens AR. Back Pain During $6^{\circ}$ Head-Down Tilt Approximates That During Actual Microgravity. Aviat Space Environ Med. 1995; 66:256-9.

- Kershner D, Binhammer R. Intrathecal ligaments and nerve root tension: possible sources of lumbar pain during spaceflight. Aviat Space Environ Med 2004; 75 (4): 354-8.

- $\quad$ Putcha L, Berens KL, Marshburn TH, Ortega HJ, Bilica RD. Pharmaceutical use by U.S. astronauts on Space Shuttle missions. Aviat Space Environ Med 1999; 70: 705-708.

- Sayson JV, Hargens AR. Pathophysiology of Low Back Pain during Exposure to Microgravity. Aviat Space Environ Med 2008; 365-73. 


\section{References}

- Scheuring, et al. NASA's Operational and Research Summit. August 23-25, 2005. Summit Recommendations. NASA/TM 2007-214766. September 2007.

- Styf JR, Ballard R, Fechner K, Waterpaugh D, et al. Height increase, neuromuscular function, and back pain during 6 degree head-down tilt with traction. Aviat Space Environ Med 1997; 68 (1): 24-9.

- Styf JR, Hutchinson K, Carlsson S, et al. Depression, mood state, and back pain during microgravity conditions. Psychom Med 2001; 63: 862-4.

- Thornton WE, Hoffler GW, Rummel JA. Anthropometric changes and fluid shifts. In: Johnson RS, Dietlein LF eds, biomedical results from skylab. Washinon DC. NASA SP377. 1977; 330-338.

- Wing PC, Tsang IK, Susak L, et al. Back pain and spinal changes in microgravity. Orthop Clin North Am 1991; 22: 255-62. 